IRSTI 31.23 .99

\author{
${ }^{1,2}$ O.M. Nassar, ${ }^{3,4 *}$ M.H. El-Sayed, ${ }^{5}$ I.A. Elsehemy \\ ${ }^{1}$ Department of Home Economics, Northern Border University, Kingdom of Saudi Arabia \\ ${ }^{2}$ Nutrition and Food Sciences Department, Faculty of Home Economics, Minufiya University, Minufiya, Egypt \\ ${ }^{3}$ Department of Biology, Faculty of Science and Arts, Northern Border University, Kingdom of Saudi Arabia. \\ ${ }^{4}$ Department of Botany and Microbiology, Faculty of Science, Al-Azhar University, Cairo, Egypt \\ ${ }^{5}$ Department of Natural and Microbial Products Chemistry, National Research Centre, Cairo, Egypt \\ *e-mail:m_helal2007rm@yahoo.com
}

\title{
Estimation of total phenolic contents and antioxidant capacities in some green and black tea of Saudi Arabia markets and evaluation of their antibacterial activity
}

\begin{abstract}
Tea is the most commonly consumed beverage in the world after water and considered a good antioxidant nutrient against free radical reactions. Teas are classified into more than one type depending on the manufacturing process. Green and black tea leaves are rich in phenolic compounds that are known for their antioxidant activity, having a beneficial effect on human health. The objective of this study was to determine phenolic content, antioxidant capacities as well as the antibacterial activity of green and black tea for the most popular brands in Saudi Arabia, Lipton and Rabea. The results showed that the content of polyphenols was higher for green brands $524.10 \pm 11.8$ and $553.75 \pm 14.0 \mathrm{mg} / \mathrm{g}$ than black brands 468.70 \pm 10.5 and $466.25 \pm 6.8 \mathrm{mg} / \mathrm{g}$ for Lipton and Rabea types respectively. Moreover, it was found that all tea types exhibited high antioxidant activity, but green tea brands were higher 93.94 and $94.08 \%$ than black brands 93.64 and $93.32 \%$ for Lipton and Rabea brands respectively. Test of antibacterial activity showed that green tea was more effective in inhibiting the growth of the test organisms than black tea, where it showed antibacterial activity with a mean diameter of inhibition zone ranged from $9.0 \pm 0.22$ to13.0 \pm $0.24 \mathrm{~mm}$ in comparison with black tea $9.0 \pm 0.20$ to $11.0 \pm 0.10 \mathrm{~mm}$. The present study indicated that no significant differences were noted in total phenolic contents and antioxidant activities for black and green tea. but Rabea green tea exhibited stronger antibacterial activity than black tea brands. To our knowledge, no studies have so far been done to compare these properties of two commercial black and green teas available in the markets of Saudi Arabia.
\end{abstract}

Key words: green, black tea, total phenolic content, radical scavenging activity, Saudi Arabia.

\section{Introduction}

In the last decades, lots of epidemiological studies were focused on bioactive phytochemicals such as phenolic compounds due to their beneficial effect on human health. It has been suggested that an initial cause of most chronic diseases is a free radical attack on biomolecules; thus, consumption of foods rich in phenolic compounds that are capable of the scavenging of reactive species may be a mechanism of protection recommending those foods for maximum health benefits $[1 ; 2]$. Historically, tea has important roles not only as ancient health therapy but also as a subject of the visual and literary arts. Tea was painted, drawn and figured on textiles and ceramics. Its shape, color, perfection and social interac- tions were described in many Odes [3; 4]. Tea is the most widely consumed drink in the world after water. It has been cultivated and consumed for more than 2000 years. Tea comes from the leaves of two classes of Camellia sinensis plant: assamica and sinensis, which originate in China and Southeast Asia $[5 ; 6]$. Teas are classified into three major types depending on the manufacturing process. Non-fermented green tea is produced by drying and steaming the fresh leaves to inactivate the polyphenol oxidase and thus, oxidation does not occur. Semi-fermented oolong tea is produced when the fresh leaves are subjected to a partial fermentation stage before drying. Fermented black and red (Pu-Erh) teas undergo a post-harvest fermentation stage before drying and steaming. However, the manufacturing process of black and red teas 
is not identical, since the fermentation of black tea is due to oxidation catalyzed by polyphenol oxidase, while the fermentation of red tea is attained by using microorganisms $[7 ; 8]$. The percentage of each type of tea produced and consumed in the world is $78 \%$ black, 20\% green and 2\% oolong tea [9]. Among the different types of tea, green tea is now preferred as it has much more positive health benefits in comparison to other natural products [10]. Tea has a complex structure, which contains polyphenols, amino acids, proteins, alkaloids, minerals, carbohydrates, volatile compounds and trace elements [11]. Due to the presence of polyphenols, many scientific studies have proved the health benefits of tea such as anticarcinogenic, anti-oxidant, anti-aging, anti-mutagenic, anti-viral, anti-bacterial, and anti-inflammatory properties $[12 ; 13]$. The antimicrobial effect of tea was first demonstrated almost a century ago, in 1906, in the laboratory by McNaught, who showed that brewed black tea killed Salmonella typhi and Brucella melitensis. Thus, he recommended that the water bottles of troops should be filled with tea in order to prevent outbreaks of infections due to these agents. The precise antimicrobial spectrum of tea is difficult to be defined due to variation in definitions of 'susceptible' and 'resistant' as well as due to variation in the methods of testing, that have been used [14]. Tea polyphenols are also known for their antibacterial activity. In general, antibacterial activity decreases when the extent of tea fermentation is increased, implying stronger activity in green tea than black tea $[15 ; 16]$. Green tea catechins, particularly EGCG and ECG, have antibacterial activity against both Grampositive and Gram-negative bacteria [17-19]. There are many types of tea (local and exotic) commonly consumed in Saudi Arabia. Most of these teas are traded and consumed without knowing their positive health benefits. So, comparing these teas with its chemical and biological activities is greatly required. Thus, the purpose of our research was to compare the total phenolic content, antioxidant capacities and antibacterial activity of two popular black and green tea brands from local Saudi markets by using several different methods. According to our knowledge, this is the first study to compare these characteristics of the most common green tea brands available in the Saudi markets.

\section{Materials and methods}

Tea samples. Camellia sinensis green teas (Lipton and Rabea), and black teas (Lipton and Rabea) were purchased from some supermarkets of Rafha

Int. j. biol. chem. (Online) governorate at the Northern Border region in Kingdom of Saudi Arabia. The tea samples were stored in a cool dry place before analysis.

Chemicals. 1,1-diphenyl-2-picrylhydrazyl (DPPH) used as the source of free radicals and Folin-Ciocalteu's phenol reagent used for estimation of total phenolic content were purchased from SigmaAldrich Chemical Co. (Pool, UK).

Samples and extract preparation. Two different brands of commercial black and green tea, purchased from the local markets (Lipton classic and Rabea tea), were used in this study. Tea samples were extracted using the hot water method [20]. Teas $(25 \mathrm{~g})$ were extracted with $250 \mathrm{ml}$ of hot water three times, with continuous swirling at $120 \mathrm{rpm}$ in an orbital shaker, for $1 \mathrm{~h}$ each time. The boiling water was allowed to cool throughout the extraction process to mimic tea brewing. After filtration under suction through Whatman No. 1 filter paper, the residues were re-extracted again with $250 \mathrm{ml}$ of hot water. The water in the extracts was removed using a freeze dryer. Dried extracts were kept at $-20^{\circ} \mathrm{C}$ in a freezer for further analysis.

Folin-ciocalteu assay. Total phenolic content (TPC) of extracts was determined using the FolinCiocalteu method $[21 ; 22]$. Samples $(300 \mu 1$, in triplicate) were introduced test tubes wrapped in aluminum foil followed by addition of $1.5 \mathrm{ml}$ of $\mathrm{FC}$ reagent (10 times dilution) and $1.2 \mathrm{ml}$ of sodium carbonate solution $(7.5 \% \mathrm{w} / \mathrm{v})$. The tubes were allowed to stand in the dark for 30 min before absorbance was measured at $765 \mathrm{~nm}$. TPC was expressed as gallic acid equivalent (GAE) in $\mathrm{mg} / \mathrm{g}$ of sample. The calibration equation for gallic acid was $\mathrm{y}=0.0111 \mathrm{x}+0.0148$ $(\mathrm{R} 2=0.9998)$.

DPPH radical scavenging assay. Antioxidant activity was measured using the DPPH radical scavenging assay $[22 ; 23]$. Different dilutions of the extracts $(1 \mathrm{ml})$ were added to $2 \mathrm{ml}$ of DPPH $(5.9 \mathrm{mg} / 100 \mathrm{ml}$ methanol) in test tubes wrapped in aluminum foil. Absorbance (A) was measured at $517 \mathrm{~nm}$ after 30 min incubation in the dark. All measurements were made with distilled water as a blank. The scavenging ability $(\%)$ of the samples was calculated as $\left(\mathrm{A}_{\text {con- }}\right.$ trol $\left.\left.-\mathrm{A}_{\text {sample }}\right) / \mathrm{A}_{\text {control }} \times 100\right)$ and calculated as $\mathrm{IC}_{50}$, the concentration of sample needed scavenge DPPH free radicals by $50 \%$. IC50 was expressed as ascorbic acid equivalent antioxidant capacity (AEAC) using the equation: $\mathrm{AEAC}\left(\mathrm{mg} \mathrm{AA} / \mathrm{g}\right.$ sample) $=\mathrm{IC}_{50}(\mathrm{AA}) /$ $\mathrm{IC}_{50}($ sample $) \times 10^{5}$. The $\mathrm{IC}_{50}$ of AA used for calculation of AEAC was $0.00387 \mathrm{mg} / \mathrm{ml}$.

Disc-diffusion method. Antibacterial activity of extracts and fractions of green and black teas were 
tested against Gram-positive Bacillus subtilis ATCC 6633 and Staphylococcus aureus ATCC 6538, and against Gram-negative Pseudomonas aeruginosa ATCC 9027 and Escherichia coli ATCC 7839. Antibacterial activity was measured using the disc-diffusion method [24]. Inoculums $(100 \mu \mathrm{l})$ were spread evenly onto $20 \mathrm{ml}$ Mueller-Hinton agar set in $90-\mathrm{mm}$ Petri dishes using a sterile cotton swab. Sterilized paper discs (6-mm diameter) were impregnated with plant samples (2 mg per disc) using a micropipette and firmly placed onto the inoculated agar ensuring even distribution to avoid overlapping of zones. Streptomycin susceptibility discs $(10 \mu \mathrm{g})$ were used as positive controls. After incubation overnight at $37^{\circ} \mathrm{C}$, the minimum inhibitory dose (MID) or lowest concentration of extract or fraction in $\mathrm{mg} /$ disc required to show a zone of inhibition was recorded $[25 ; 26]$.

Statistical analysis. The data were statistically analyzed using Microsoft Excel 2019. Results with $\mathrm{p}<0.05$ were considered statistically significant. All experiments were performed in triplicate and the values were expressed as mean $\pm \mathrm{SD}$. The differences between the samples were assessed using single factor analysis of variance (ANOVA).

\section{Results and discussion}

Tea is consumed more than any other beverage worldwide [27]. It is a hot water infusion of the dried, young leaves and/or buds of the evergreen Camellia sinensis plant [28; 29]. In 2012, 4.884 million tons of tea was produced and consumed globally [30]. The chemical composition of tea is complex and not completely understood. The detailed investigations which have been made were done mainly to understand how tea gets its characteristic flavor and appearance. In the present study, hot water extract of two popular black and green tea brands from local Saudi markets (Lipton and Rabea tea) were prepared for estimation of total phenolic content, antioxidant capacities and antibacterial activity. Hot water was used for extraction since it is the traditional way of brewing tea and previous studies have shown it to be an efficient way of extracting tea $[31 ; 32]$. Studies have shown that water temperature is an important factor when extracting tea. Significantly higher yields of hot water than cold water extraction of green tea and stronger radical scavenging activity of oolong tea extracted with hot water of increasing temperature have been reported [33; 34]. For green, oolong, and black teas, extraction with water at $100^{\circ} \mathrm{C}$ for 3 min yielded higher total flavanol content than extraction with water at 60 and $80^{\circ} \mathrm{C}$ [35].

Total phenolic content (TPC). Polyphenols are a class of chemical constituents with one or more hydroxyl groups associated to the aromatic arene (phenyl) ring. Consequently, they are considered as one of the most potent antioxidative compounds that contribute to the antioxidant activity [36]. Hence, it is important to quantify polyphenol content and to estimate its contribution to antioxidant activity. Total phenolic contents of black teas (Lipton and Rabea) and green teas (Lipton and Rabea) brands were expressed as gallic acid equivalent. The results showed that the content of polyphenols was higher for green brands $524.10 \pm 11.8$ and $553.75 \pm 14.0$ $\mathrm{mg} / \mathrm{g}$ than black brands $468.70 \pm 10.5$ and $466.25 \pm$ $6.8 \mathrm{mg} / \mathrm{g}$ for Lipton and Rabea brands respectively (Table 1).

Table 1 - Total phenolic content (TPC) of extracts of Camellia sinensis teas

\begin{tabular}{|c|c|c|c|}
\hline No & Type & Brand (County) & $\mathrm{TPC}^{\mathrm{a}}$ (mg GAE/g) \\
\hline \multirow{2}{*}{1} & \multirow{2}{*}{ Black } & Lipton (United Arab Emirates) & $468.70 \pm 10.5$ \\
\hline & & Rabea (Saudi Arabia) & $466.25 \pm 6.8$ \\
\hline \multirow{2}{*}{2} & \multirow{2}{*}{ Green } & Lipton (United Arab Emirates) & $524.10 \pm 11.8$ \\
\hline & & Rabea (Saudi Arabia) & $553.75 \pm 14.0$ \\
\hline
\end{tabular}

Our results showed that the concentration of total phenol content was high in both brands especially in the green teas, this result may be referred to the high antioxidant activity of tea catechins, which are mainly found in green tea. The concentration of TPC obtained in this study is slightly lower than TPC obtained in the previous study concerned with the comparison of TPC activity of two popular green tea beverages available in the local market of Saudi Arabia recorded high phenolic content for the two green brands [37]. 
DPPH radical scavenging activity. DPPH assay is used to evaluate the free radical scavenging activity of hydrogen donating antioxidants in many plant extracts. DPPH is a stable free radical with a dark violet color. This method is based on the principle that DPPH accepts a hydrogen atom from the antioxidant, resulting in the reduction of DPPH to DPPH2, the violet color changes to yellow with a consequent decrease in absorbance at $517 \mathrm{~nm}$. The efficiency of the antioxidant compound is measured by its ability to change color. The percentage of inhibition caused by green tea brands was higher 93.94 and $94.08 \%$ than black brands 93.64 and $93.32 \%$ for Lipton and Rabea brands respectively (Figure 1).

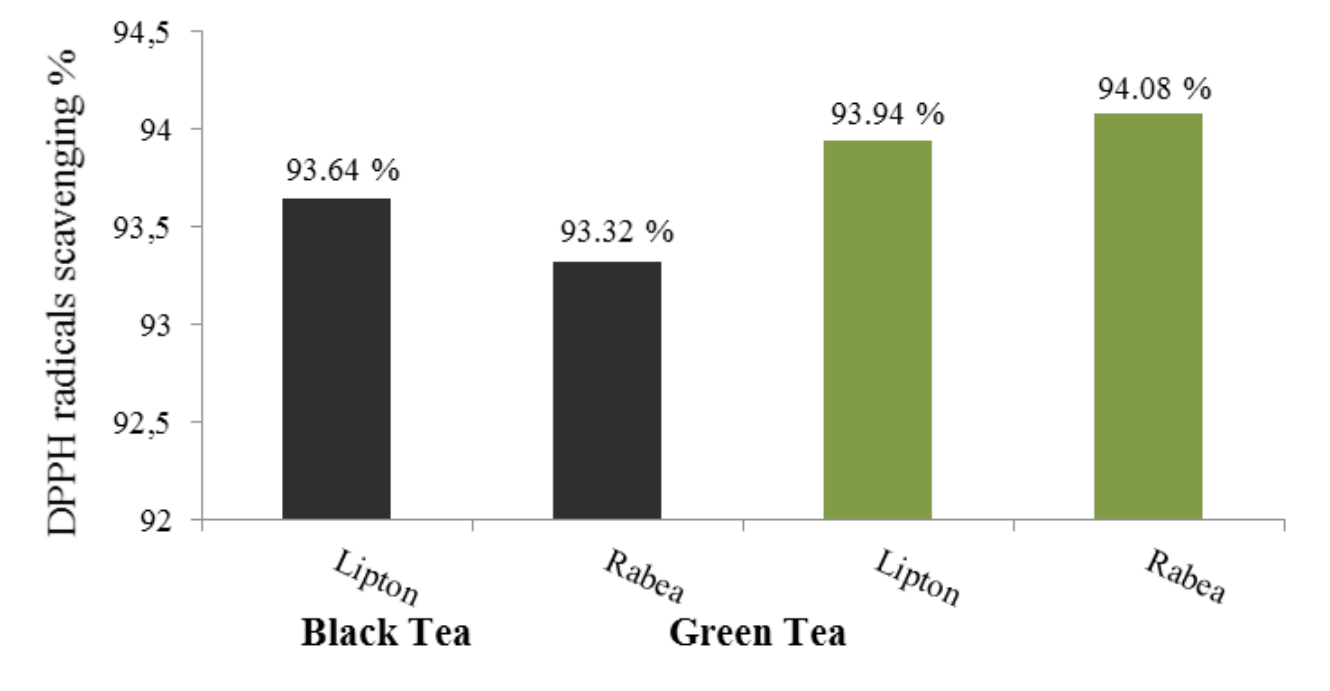

Figure 1 - Radical scavenging activity by black and green (Lipton and Rabea) teas The value expressed as means $\pm \mathrm{SD}(\mathrm{n}=3)$. Compression of means was made using unpaired t-test $(\mathrm{P}>0.05)$

Results demonstrate that black and green of the two brands have the ability to scavenge free radicals. Therefore, both have the same high antioxidant activity. The presence of chlorophyll and pheophitin in green tea extract could explain the higher DPPH scavenging activity in these samples (Figure 1). The main green tea catechins are Epicatechin (EC), epigallocatechin (EGC), epicatechin gallate (ECG) and epigallocatechin gallate (EGCG) [38]. In general, Epigallocatechin gallate is the most powerful catechins in tea and it is responsible for the majority of the biological activity of green tea. It is well known that green tea has greater total catechins than black tea due to the fermentation process; catechins in the black tea are reduced as they are converted to the flavins and thearubigins [39]. Moreover, our results showed that the two brands have the ability to scavenge free radicals. Studies conducted by Omar et al. [37] and Gramza et al. [40], indicated that the analysis of DPPH free radicals scavenging ability by green tea showed higher radicals scavenging efficiency than black tea extract.

Int. j. biol. chem. (Online)
Antibacterial properties. Antibacterial activity of hot water extracts of black and green teas are recorded in Table 2 and represented in Figure 2.

The results obtained showed that green tea was more effective in inhibiting the growth of the test organisms than black tea, where it was showed antibacterial activity with mean diameter of inhibition zone ranged from $9.0 \pm 0.22$ to $13.0 \pm 0.24 \mathrm{~mm}$ in comparison with black tea $9.0 \pm 0.20$ to $11.0 \pm 0.10 \mathrm{~mm}$. Furthermore, it was found that green Rabea brand was the most active one where it was active against all of the bacterial test organisms, while the weakest one was in case of black Rabea brand where it exhibited activity against $B$. subtilis ATCC 6633 with inhibition zone diameter $9.0 \pm 0.20 \mathrm{~mm}$ and non-active against the other test organisms. The inhibition of tea extracts against $P$. aeruginosa and $E$. coli has been reported $[16 ; 18]$ although an earlier study has explicitly reported that tea extracts are not effective against $P$. aeruginosa and E. coli [19]. The disparity in findings could be due to different strains of bacteria used, and to the different concentrations and 
types of extracts investigated. Gram negative bacteria are less susceptible to antibiotics as their outer membrane of lipoproteins and lipopolysaccharides is able to regulate the access of antibacterial agents into the underlying structures [41]. Several studies have shown that catechins from green and black teas, particularly EGCG and ECG, inhibited the growth of many bacterial species [17].

Table 2 - Antibacterial activity of extracts of Camellia sinensis teas using the disc-diffusion method

\begin{tabular}{|c|c|c|c|c|c|}
\hline \multirow{3}{*}{ Type } & \multirow{2}{*}{ Brand (County) } & \multicolumn{3}{|c|}{ Inhibition zone diameter (mm) } \\
\cline { 3 - 6 } & & \multicolumn{2}{|c|}{ Gram positive } & \multicolumn{2}{c|}{ Gram negative } \\
\cline { 3 - 6 } & & $\begin{array}{c}\text { B. subtilis } \\
\text { ATCC 6633 }\end{array}$ & $\begin{array}{c}\text { S. aureus } \\
\text { ATCC } 6538\end{array}$ & $\begin{array}{c}\text { P. aeruginosa } \\
\text { ATCC 9027 }\end{array}$ & $\begin{array}{c}\text { E. coli } \\
\text { ATCC 7839 }\end{array}$ \\
\hline \multirow{2}{*}{ Black } & Lipton (United Arab Emirates) & $11.0 \pm 0.10$ & 0.0 & 0.0 & 0.0 \\
\cline { 2 - 6 } & Rabea (Saudi Arabia) & $9.0 \pm 0.20$ & 0.0 & 0.0 & 0.0 \\
\hline \multirow{2}{*}{ Green } & Lipton (United Arab Emirates) & $13.0 \pm 0.24$ & 0.0 & 0.0 & $12.0 \pm 0.15$ \\
\cline { 2 - 6 } & Rabea (Saudi Arabia) & $13.0 \pm 0.15$ & $9.0 \pm 0.22$ & $11.0 \pm 0.10$ & $9.0 \pm 0.25$ \\
\hline
\end{tabular}
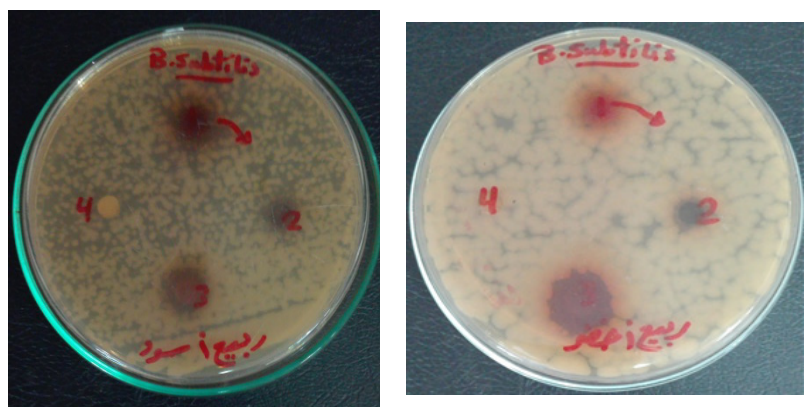

A
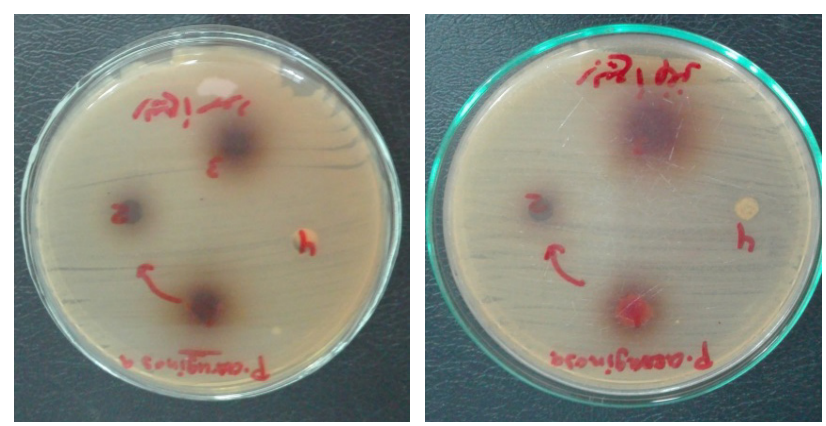

C
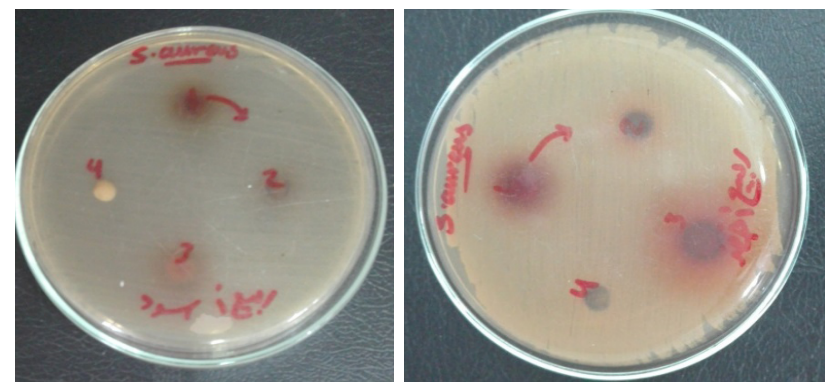

B
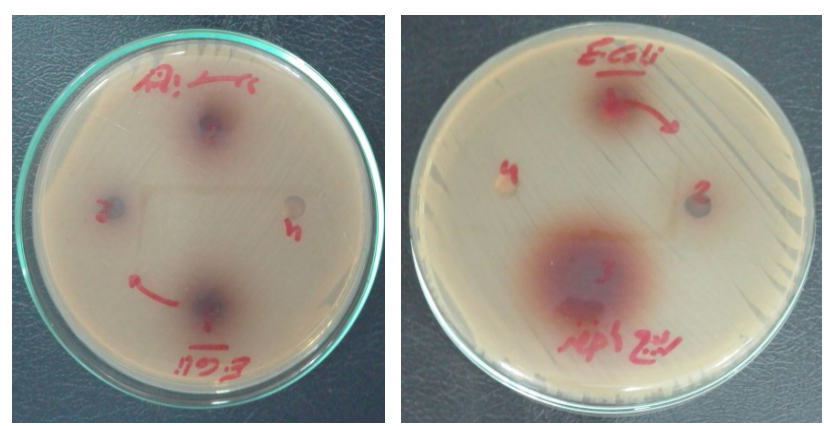

D

Figure 2 - Antibacterial activity of black and green teas (Lipton and Rabea) against (A): B. subtilis, (B): S. aureus, (C) P. aeruginosa and (D): E. coli.

Contrary to findings from this study, earlier studies have reported that black teas inhibited the growth of Gram positive bacteria [18; 42]. Extracts of green tea have been reported to be more effective in inhibiting bacterial growth than black tea [15]. In general, antibacterial activity decreased when the extent of tea fermentation increased $[16 ; 19]$.

\section{Conclusion}

Our research work showed that green and black tea of the most popular brands in Saudi Arabia, Lipton and Rabea showed similar activity in their total phenolic contents $(524.10 \pm 11.8$ to $553.75 \pm 14.0$ and $466.25 \pm 6.8$ to $468.70 \pm 10.5 \mathrm{mg} \mathrm{GAE} / \mathrm{g}$ ) and 
antioxidant activity (93.64 to $93.32 \%$ and 93.94 to $94.08 \%$ ). However, green tea exhibited stronger antibacterial activity against all tested strains $(0.0$ to $13.0 \mathrm{~mm}$ ) than black tea which was active against only one strain $(0.0$ to $11.0 \mathrm{~mm})$. Continued researches are needed to further the current knowledge on the health-promoting effects of this popular beverage using different supplements by different mechanisms.

\section{Acknowledgement}

Olfat M. Nassar, Mohamed H. El-Sayed and Islam Abd Elmageed Elsehemy gratefully acknowledge the approval and support of this research study by the grant No. 7279-SAR-2017-1-8-F from Deanship of Scientific Research, Northern Border University, Arar, KSA.

\section{References}

1.Pellegrini N., Serafini M., Colombi B., Del Río D., Salvatore S., Bianchi M., Brighenti F. (2003) Total antioxidant capacity of plant foods, beverages, and oils consumed in Italy assessed by three different in vitro assays. J. Nutr., vol. 133, no. 9, pp. 28122819.

2. Pérez-Jiménez J., Arranz S., Tabernero M., Diaz-Rubio M.E., Serrano J., Gońi I., Saura-Calixto F. (2008) Update methodology to determine antioxidant capacity in plant foods, oils and beverages: extraction, measurement and expression of results. Food Res. Int., vol. 41, no. 3, pp. 274-285.

3. Marchand F., Desharnais J. (2014) Tea: History, Terroirs, Varieties: Kevin Gascoyne, François Marchand, Jasmin Desharnais, Hugo Americi editors. $2^{\text {ed }}$ edition. Firefly Books. pp. 41-47.

4. Panda H. (2016) The Complete Book on Cultivation and Manufacture of Tea. $2^{\text {ed }}$ revised edition. Asia Pacific Business Press Inc. pp. 321-325.

5. Quan T., Hang V., Ha H., Glang L. (2007) Total polyphenols, total catechin content and DPPH free radical scavenger activity of several types of Vietnam commercial green tea. Sci. Technol. Devel., vol. 10 , no. 1 , pp. 5-11.

6. Rabiul I., Gias Uddin M., Mahfuzur R., Yousuf A. (2013) Short communication: caffeine and total polyphenol contents of market tea cultivated and processed in Bangladesh. Malaysian J. of Nut., vol. 19, no. 1, pp. 143-147.

7. Cabrera C., Artacho R., Gimenez R. (2006) Beneficial effects of green tea: A Review. J. Am. Coll. Nutr., vol. 25, no. 1, pp. 79-99.
8. McKay L., Blumberg B. (2002) The role of tea in human health: An update. J. Am. Coll. Nutr., vol. 21, no. 1, pp. 1-13.

9. Chan W., Lim Y., Chew L. (2007) Antioxidant activity of Camellia sinensis leaves and tea from a lowland plantation in Malaysia. Food Chem., vol. 102, no. 1, pp. 1214-1222.

10. Kusmita L., Puspitaningrum I., Limantara L. (2015) Identification, isolation and antioxidant activity of pheophytin from green tea (Camellia sinensis (L.) Kuntze). Procedia Chem., vol. 14, no. 1, pp. 232-238.

11. Reto M., Figueira E., Filipe M., Almeida M. (2007). Chemical composition of green tea (Camellia sinensis) infusions commercialized in Portugal. Plan. Foods Hum. Nut., vol. 62, no. 1, pp. 139-144.

12. Sangsrichan S., Ting R. (2010) Antioxidation and radical scavenging activities and tyrosinase inhibition of fresh tea leaves, Camellia sinensis. Sci. J. Ubon Ratchathani Univ., vol. 1, no. 1, pp. 76-81.

13. De la Luz Cádiz-Gurrea M., Fernández-Arroyo S., Segura-Carretero A. (2014) Pine bark and green tea concentrated extracts: antioxidant activity and comprehensive characterization of bioactive compounds by HPLC-ESIQTOF-MS. Int. J. Molec. Sci., vol. 15, no. 1, pp. 20382-20402.

14. Eugenia Ch Y. (2012) Recent patents on antibacterial, antifungal and antiviral properties of tea. Recent Pat. on Anti-Inf. Drug Disc., vol. 7, no. 1, pp. 60-65.

15. Tiwari R., Bharti S., Kaur H., Dikshit R., Hoondal G. (2005). Synergistic antimicrobial activity of tea and antibiotics. Indian J. Med. Res., vol. 122, no. 1 , pp. $80-84$.

16. Almajano M.P., Carbó R., Jiménez J.A., Gordon M.H. (2008) Antioxidant and antimicrobial activities of tea infusions. Food Chem., vol. 108, no. 1, pp. 55-63.

17.Hamilton-Miller J. (1995) Antimicrobial properties of tea (Camellia sinensis L.). Antimicrob. Agents Chemother., vol. 39, no. 1, pp. 2375-2377.

18. Bancirova M. (2010) Comparison of the antioxidant capacity and the anti-microbial activity of black and green tea. Food Res. Int., vol. 43, no. 1, pp. 1379-82.

19.Toda M., Okubo S., Hiyoshi R., Shimamura T. (1989) The bactericidal activity of tea and coffee. Lett. Appl. Microbiol., vol. 8, no. 1, pp. 123-125.

20. Chan W., Lim Y., Chong L., Tan L., Wong K. (2010) Antioxidant properties of tropical and temperate herbal teas. J. Food Compos. Anal., vol. 23, no. 1, pp. 185-9. 
21.Kähkönen P., Hopia I., Vuorela J., Rauha P., Pihlaja K., Kujala S, et al. (1999) Antioxidant activity of plant extracts containing phenolic compounds. J. Agric. Food Chem., vol. 47, no. 1, pp. 3954-62.

22. Wong S., Lim Y., Abdullah N., Nordin F. (2011) Antiproliferative and phytochemical analyses of leaf extracts of ten Apocynaceae species. Phcog. Res., vol. 3, no. 1, pp. 100-106.

23. Miliauskas G., Venskutonis P.R., van Beek T.A. (2004) Screening of radical scavenging activity of some medicinal and aromatic plant extracts. Food Chem., vol. 85, no. 1, pp. 231-237.

24. Chung Y., Chung Y., Ngeow F., Goh H., Imiyabir Z. (2004) Antimicrobial activities of Malaysian plant species. Pharm. Biol., vol. 42, no. 1, pp. 292300.

25. Mackeen M., Ali M., El-Sharkawy H., Manap Y., Salleh M., Lajis H, et al. (1997) Antimicrobial and cytotoxic properties of some Malaysian traditional vegetables (ulam). Pharm. Biol., vol. 35, no. 1, pp. 174-178.

26. Chan W., Ng P., Tan V., Low Y. (2011) Antioxidant and antibacterial properties of Alpinia galanga, Curcuma longa and Etlingera elatior (Zingiberaceae). Phcog. J., vol. 3, no. 1, pp. 54-61.

27.Ho C., Lin K., Shahidi F. (2008) Tea and tea products: chemistry and health-promoting properties. Boca Raton: CRC Press. pp. 215-219.

28. Chu C., Juneja, R. (1997) General chemical composition of green tea and its infusion. Chemistry and applications of green tea. Boca Raton: CRC Press. pp. 13-22.

29. Saberi H. (2010) Tea: a global history. London: Reaktion Books. pp. 94-95.

30. Shannon E., Jaiswal K., Abu-Ghannam N. (2017). Polyphenolic content and antioxidant capacity of white, green, black, and herbal teas: a kinetic study. Food Res., vol. 2, no. 1, pp. 1-11.

31.Farhoosh R., Golmovahhed G.A., Khodaparast M.H. (2007) Antioxidant activity of various extracts of old tea leaves and black tea wastes (Camellia sinensis L.). Food Chem., vol. 100, no. 1, pp. 231-236.

32.Nkubana A., He Q. (2008) A comparative study of antioxidant activity between black tea from Rwandan highlands with green and oolong teas from
China. Int. J. Food Saf. Nutr. Public Health, vol. 1, no. 1, pp. 159-66.

33.Su X., Duan J., Jiang Y., Shi J., Kakuda Y. (2006) Effects of soaking conditions on the antioxidant potentials of oolong tea. J. Food Compos. Anal., vol. 19 , no. 4 , pp. 348-353.

34.Lin D., Liu H., Mau L. (2008) Effect of different brewing methods on antioxidant properties of steaming green tea. LWT-Food Sci. Technol., vol. 41, no. 9, pp. 1616-1623.

35.Horžić D., Komes D., Belscak A., Ganic K.K., Ivekovic D., Karlovic D. (2009) The composition of polyphenols and methylxanthines in teas and herbal infusions. Food Chem., vol. 115, no. 2, pp. 441-448.

36. Andjelković M., Van Camp J., De Meulenaer B., Depaemelaere G., Socaciu C., Verloo M., Verhe R. (2006) Iron-chelation properties of phenolic acids bearing catechol and galloyl groups. Food Chem., vol. 98 , no. 1, pp. 23-31.

37. Omar U., Shorbaji A., Arrait E., Al Agha T., Al-Marzouki H., Al Doghaither H., Al-Ghafari A. (2016) Comparative study of the antioxidant activity of two popular green tea beverages available in the local market of Saudi Arabia. Nat. Sci., vol. 8, no. 1, pp. 227-234.

38. Sabouri S., Geng J., Corredig M. (2015) Tea polyphenols association to caseinate-stabilized oilwater interfaces. Food Hydrocoll., vol. 51, no. 1, pp. 95-100.

39. Carloni P., Tiano L., Padella L., Bacchetti T., Customu C., Kay A., Damiani E. (2013) Antioxidant activity of white, green and black tea obtained from the same tea cultivar. Food Res. Int., vol. 53, no. 1, pp. 900-908.

40.Gramza A., Pawlak-Lemanska K., Korczak J., Wasowicz E., Rudzinska M. (2005) Tea extracts as free radical scavengers. Polish J. Environ. St., vol. 14 , no. 1 , pp. 861-867.

41.Unten L., Koketsu M., Kim M. (1997) Anti-discoloring activity of green tea polyphenols on $\beta$-carotene. J. Agric. Food Chem., vol. 45, no. 6, pp. 2009-2012.

42.Chopra I., Greenwood D. (2001) Antibacterial agents: Basis of action. In: Battista J, editor. Encyclopedia of Life Sciences. Hoboken, New Jersey: Wiley; p. 1-8. 